\title{
Enterprise Java Bean
}

National Cancer Institute

\section{Source}

National Cancer Institute. Enterprise Java Bean. NCI Thesaurus. Code C43620.

The server-side component architecture for the Java 2 Platform, Enterprise Edition (J2EE)

platform. EJB technology enables rapid and simplified development of distributed,

transactional, secure and portable applications based on Java technology. (Sun

Microsystems) 